\title{
浅析初中体育教学方法的选择及其创新应用
}

\author{
李德锋 \\ 重庆市涪陵第十七中学校 \\ DOI:10.32629/er.v2i3.1734
}

[摘 要] 体育作为初中教育教学体系中不可或缺的一门重要学科,无论是从学科能力来说, 还是从学科的内容而言, 与其它学 科有着明显区别。而初中体育教学所具备的这些特点, 反应到体育教学方法的应用上也同样具有其独特的一面。因此为了提 高初中体育教学质量,本文对初中体育教学方法应用的现状及其合理选择与创新应用进行了探讨分析。

[关键词] 初中体育教学方法; 应用; 现状; 选择; 创新

\section{1 初中体育教学方法应用的现状分析}

随着学校体育教学改革的不断深入, 绝大多数初中体育 任课教师都意识到了教学方法的重要性, 而且很多体育任课 教师也对近些年新兴的体育教学方法有了不同程度了解, 甚 至有一部分初中体育任课教师已经有意识的在所开展的初 中体育教学实践中积极的进行了各种新的体育教学方法应 用。由此可知, 初中体育教学方法的应用和发展总体现状还 是比较好, 但是同时在实地走访和资料检索与分析过程中, 也发现目前在初中体育教学中, 教学方法应用还存在过于单 一、老套, 所开展的体育教学活动不够活跃有效; 教学的组 织形式过于单调; 对新的教学方法理解存在过于肤浅或是存 在误区等诸多问题, 以至于影响了初中体育教学方法应用的 有效性。

\section{2 初中体育教学方法的选择分析}

初中体育教学活动开展过程中, 为了确保体育教学方法 的有效应用, 必须注意教学方法的选择: (1) 选择初中体育教 学方法时, 应注意考虑初中体育教学的具体目标和具体任 务。通常说来, 不同的教学目标和教学任务, 往往需要不同的 教学方法来加以实现和完成。例如: 在讲授新的课程内容时, 要尽可能选用有助于突出新内容讲授的体育教学方法, 而在 开展练习课或者是复习课教学时, 则尽可能选用能够留给学 生足够的练习时间和练习机会的体育教学方法。(2) 选择初 中体育教学方法时, 应注意考虑教学内容的特点。教学内容 不同所需要的教学方法也不尽相同, 例如: 同样是跑步教学, 在田径教学中, 则要以能够促进学生跑动速度提高的教学方 法为主, 而在篮球教学中, 则需要采用能够结合篮球教学特 点的教学方法, 如, 带球跑、侧身跑等等。(3) 选择初中体育 教学方法时, 应注意考虑学生的身心特点等实际情况。例如, 在针对初一学生开展体育教学活动时, 由于初一学生多处于 十二三岁左右的年纪, 活泼好动、体育课的学习积极性高, 但是同时又具有明显的纪律性不够强、学习自觉性不够高等 特点, 如果离开了体育任课教师的统一组织和管理, 很难完 成任课教师提出的学习任务, 再加上初一学生的体育水平相 较于中学高年级的学生而言水平较低, 在开展技术动作练习 中, 如果离开了老师的临场指导, 一般很少有学生能够具有
自我改进技术和纠正其它学生错误动作的能力, 因此不但在 练习中很难提高自己的技术动作水平, 甚至还会因此造成错 误的动力定型, 为体育教学活动的开展造成不利影响。因此 针对初一学生的这些特点, 就可以知道, 在针对初一学生来 开展体育教学活动时, 采用集中教学的教学方法会比分组教 学方法更具成效, 而反之, 在针对中学高年级的学生开展体 育教学时, 由于中学高年级的学生已经具备了较好的纪律意 识和学习自觉性, 而且也具有了一定的体育水平, 此时采用 分组教学方式, 能够更好的激发学生的体育学习兴趣和积极 性, 相较于集中教学方法而言, 教学成效也会更加明显。(4) 选择初中体育教学方法时, 要注意考虑任课教师的自身的优 势和素养。任何教学方法都不是万能, 也没有任课教师是全 能, 并不是每一位初中体育任课教师都有能力驾驭任何一种 体育教学方法。因此在开展初中体育教学活动过程中, 为了 能够让任课教师充分发挥自己的教学优势和教学特色, 并尽 可能实现教学方法的正确、准确和创造性运用, 在选择教学 方法时, 一定要注意考虑任课教师自身的优势和素养, 所选 用的教学方法最好能够与任课教师的实际情况相结合, 有助 于发挥任课教师的优势和特长, 以此确保体育教学方法在初 中体育教学中的合理、科学应用。(5) 选择初中体育教学方 法时, 要注意考虑教学方法本身所具有的特性。任何教学方 法都具有一定的特性, 例如: 与特定教学内容的亲和性、对 特定教学设施的要求以及对特定教学对象的要求等等。简而 言之, 就是任何一种体育教学方法既有其适用范围, 同时也 具有一定的局限性, 在进行初中体育教学方法选择时, 只有 对教学方法自身所具有的特性进行充分考虑, 才能够实现教 学方法的有效应用。

\section{3 初中体育教学方法创新应用的分析}

初中体育教学过程中如何运用创新型手段提升初中体 育课堂教学效率, 是每个初中体育教育工作者都应该认真思 考的问题。在处总体育教学中进行创新, 可以有效提升教学 效率, 为学生带来更好的身体发展、德育发展与更强的学习 兴趣。体育课程是教师带领学生发展运动能力、培养学习兴 趣、提升道德品质的重要课程。在体育教学过程中, 教师运 用何种教学方法、使用何种教学手段, 直接关乎教学质量。 
在具体教学过程中, 利用游戏教学激发学生的学习兴趣, 利 用小组合作学习提升训练水平, 利用体育比赛培养学生的体 育道德风尚。具体表现为: (1) 利用游戏教学激发学生的学 习兴趣。体育教学方法创新过程中引入游戏教学, 有效培养 了体育学习兴趣。在游戏教学中, 学生的天性得到了充分尊 重, 利用有趣的游戏既能够锻炼身体机能, 又能够发展学生 的团结协作意识, 还能够有效激发学生的学习兴趣。体育游 戏教学的开展应遵循安全性、互动性、合作性、趣味性原则, 利用游戏来充分促进学生的全面发展。例如在体育游戏 “撒 网捕鱼” 的活动过程中, 组织四名学生作为 “捕鱼人”, 负责 进行 “捕鱼”。其他学生则作为 “鱼”, 负责躲避 “捕鱼人” 的追捕。游戏有着一定范围的场地, “捕鱼” 只能在场地中 进行, 出了场地的 “鱼” 算作被捕。“捕鱼” 过程是全体 “捕 鱼人”手拉手在场地中围堵 “鱼” ，“鱼” 被捕之后则加入 “捕鱼人” 参加 “捕鱼”。当 “鱼” 被捕光或剩下少量 “鱼”, 游戏宣告结束。在这个游戏中, “捕鱼人” 需要通过手拉手 的密切配合进行 “捕鱼”, “鱼” 则可以弯腰钻过 “渔网”, 因此游戏很有趣味。学生在这个游戏中不仅能够发展体育学 习兴趣, 还能够培养团队协作精神, 从而真正促进了他们的 全面发展。(2) 利用小组合作学习提升训练水平。在体育教 学中, 对学生运动能力的训练是一项重要教学任务。在体育 教学过程中, 采用小组合作学习的方式对学生进行运动能力 的训练, 使学生在发展运动能力的同时, 有效增进了同学间 的友谊, 学会了与他人合作, 学会了包容他人, 学会了尊重他 人。例如在足球的传接球训练中, 将学生分成不同的训练小 组, 每个小组 5 个人。首先进行原地传接球训练, 让 5 名学生 呈环形站开, 其中一名学生持球到场地中央, 根据自身意愿 将球传给其他 4 人中的任意一人, 得球学生则继续带球传 球。在学生对原地训练较为熟练之后, 进行动态训练, 即 5 名 学生站成环形队伍, 在球场跑动传接球, 从而有效提升了训 练水平。学生在小组合作学习过程中, 能够逐渐培养默契感, 从而发展团队精神, 增进彼此友谊, 获得社会能力发展。(3)
利用体育比赛培养学生的体育道德风尚。体育比赛是体育的 最高表现形式, 在体育教学中, 如何利用体育比赛促进教学 的开展, 是一项崭新的课题。在实际的体育教学过程中, 为学 生设置了足球比赛、篮球比赛、实心球比赛、短跑接力比赛 等丰富多彩的比赛, 真正给予学生通过比赛展示自身体育能 力的舞台。当然进行比赛教学主要是为了培养学生的体育道 德风尚, 让学生养成 “胜不骄, 败不馁” 的运动精神和 “友谊 第一, 比赛第二” 的体育风尚等, 使学生能够真正从体育课程 中获得德育发展。例如组织学生进行的 $4 \times 50$ 米短跑接力比 赛, 首先将男女生分开, 将男女生分别以每组 4 人的方式分 成小组。之后让小组成员为自己的代表队起一个响亮的名 字。接着举行入场仪式, 并安排学生进行赛前的握手致意。 随着比赛的开始, 学生都争先恐后地开始了起跑, 展现出了 勇于拼搏的体育精神。比赛结束后举行颁奖仪式, 让获奖同 学与大家再次握手, 宣告比赛结束。通过比赛有效深化了学 生对体育道德风尚的理解, 使学生的体育道德风尚获得了有 效的提升。

\section{4 结束语}

综上所述, 体育课是初中学习阶段一项基本课程, 能够 帮助学生发展身心健康。并且是培养学生体育兴趣、态度、 习惯、知识、能力等的黄金时期, 对增强学生的身体素质, 培养学生的道德和意志品质等具有重要意义, 因此必须加强 对初中体育教学方法的选择及其创新应用进行分析。

\section{[参考文献]}

[1]陈红.新课改初中体育教学的困境与对策[J].教育研 究与实践,2015,(06):25.

[2]徐丽娟.当前初中体育教学中的困境及对策分析 [J]. 教育教学坛,2014,(33):36.

[3]袁德良.新课改下初中体育教学思路与方法创新[J]. 文理导航,2015,(01):57.

[4]黄健伟.新课改下初中体育教学思路与方法创新 [J]. 课程教育研究,2017,(03):31+43. 